\title{
EFECTOS DE LA PANDEMIA EN LA FAMILIA Y EN LA SOCIEDAD ECUATORIANA.
}

\section{EFFECTS OF THE PANDEMIC ON THE ECUADORIAN FAMILY AND SOCIETY \\ Mónica Janeth Naranjo Zambrano, Lcda.}

Licenciada en Psicología (Ecuador). Maestrante en Administración del Talento Humano de la Universidad

ECOTEC, Ecuador.

monaranjo@mgs.ecotec.edu.ec

Israel André Morales Naranjo, M.D.

Tercer nivel, Médico General (Ecuador).

Maestrante en Seguridad y Salud Ocupacional de la Universidad de Especialidades Espíritu

Santo, Ecuador.

dr.israelmoralesmdb@gmail.com

Rafael Eduardo Ron Amores, MBA. Magíster en Administración y Dirección de Empresas (Ecuador).

Docente Titular Auxiliar 2 de la Facultad de Ciencias Económicas y Empresariales de la Universidad ECOTEC, Ecuador. eron@ecotec.edu.ec

\section{ARTÍCULO DE INVESTIGACIÓN}

Recibido: 17 de septiembre de 2020

Aceptado: 25 de septiembre de 2020

\section{RESUMEN}

Las pandemias en cualquier época de la historia han atacado a toda la población sin sesgo económico, religión o estrato social. Dentro del conglomerado familia, sus miembros sufren los efectos de la crisis quedándose desprotegidas de los avatares de estos virus que atacan a la humanidad. En muchas familias extensas donde algunos de sus miembros pueden ser vulnerables, el impacto mayor son las personas de tercera edad con enfermedades crónicas o enfermedades catastróficas; en ellos, la protección disminuye en cuanto a su sistema inmunológico. El objetivo de la presente investigación fue demostrar los efectos de la pandemia en la sociedad ecuatoriana, en donde se determinó a través del modelo matemático Chicuadrado que sí hay una relación directa entre el nivel de contagio y el aumento de fallecidos. Por ende, al no existir hasta el momento una vacuna que pare de forma paulatina el COVID-19, 
la salud física y psicológica se verá deteriorada, si no se hace un esfuerzo por parte de la población del cuidado y aplicación de medidas preventivas.

Palabras clave: Covid-19, Confinamiento, Familia, Salud, Pandemia

\section{ABSTRACT}

Pandemics at any time in history have attacked the entire population without economic bias, religion or social stratum. Within the family conglomerate, its members suffer the effects of the crisis, remaining unprotected from the vicissitudes of these viruses that attack humanity. In many extended families where some of their members may be vulnerable, the greatest impact is the elderly with chronic illnesses or catastrophic illnesses; in them, the protection decreases in terms of their immune system. The objective of this research was to demonstrate the effects of the pandemic in Ecuadorian society, where it was determined through the Chi-square mathematical model that there is a direct relationship between the level of contagion and the increase in deaths. Therefore, as there is not so far a vaccine to gradually stop COVID-19, physical and psychological health will deteriorate, if an effort is not made by the population to care for and apply preventive measures.

Keywords: Covid-19, Confinement, Family, Health, Pandemic

\section{INTRODUCCIÓN}

Dentro de muchas familias ecuatorianas, se han presentado situaciones críticas por causa de la pandemia, donde los altos costos médicos y la pérdida de familiares ha ocasionado problemas sociales y económicos que se han incrementado en los últimos meses, y que ha producido daños tanto físicos como psicológicos en los miembros de la familia, en esta época de pandemia se ha producido un incremento de familias con baja calidad de vida, provocando limitaciones en el ámbito social, intelectual y financiero.

Es por lo que se fundamenta la presente reflexión en torno a los problemas tanto físicos como psicológicos que puede presentar la familia en época de pandemia, de manera sistémica, donde la familia y sociedad, constituyen un todo, esto corresponde a una organización en la cual sus elementos sin excepción están intrínsecamente vinculados y no pueden separarse. Por tal motivo, es necesario destacar la importancia de la familia, así como la escuela en la formación psíquica del individuo (Dilleggi, Rosa, \& Santos, 2019).

Desde el inicio de la pandemia, la salud tanto física como psicológica de la población ha sido vulnerada, esto debido a que sus actividades normales han sido mermadas, y en algunos hogares su salud se ha visto quebrantada, para que una familia se encuentre bien es necesario que todos sus miembros se encuentren bien. Las familias que han sido mayormente golpeadas 
por la pandemia son aquellas que han requerido asistencia médica sin recibirla, para a posterior solicitar que alguien recoja a sus muertos de sus hogares, y por si esto no fuera poco, luego rogar para que se los devuelvan, y darles una adecuada sepultura, situación vivida entre finales de marzo y principios de abril.

Se conoce que cada hogar se encuentra integrado por varios integrantes, donde cada quien presenta intereses y problemas de distinta índole, donde la salud integral familiar es el reflejo que presentan cada uno de sus miembros y de las relaciones armoniosas entre ellos; es así que, las familias sanas forjarán poblaciones sanas, las cuales están aptas para todos los cambios que susciten en la sociedad, por el bienestar familiar (Armas \& Díaz, 2014).

\section{REVISIÓN TEÓRICA}

A continuación, se muestran las diferentes conceptualizaciones encontradas durante esta revisión de literatura, las mismas que conciernen al tema estudiado y que servirán para conocer algunas definiciones de la familia en tiempo de pandemia, en donde se analizarán sus características y posibles efectos por el impacto en la salud física y psicológica en la sociedad ecuatoriana.

\section{Definiciones de Familias}

El concepto familia difiere un poco, para la OMS son "los miembros del hogar emparentados entre sí, hasta un grado determinado por sangre, adopción y matrimonio", donde estos grupos sociales son unidos por vínculos de consanguinidad, filiación (biológica o adoptiva) y de alianza, incluyendo las uniones de hecho cuando son estables (OMS, 2003).

La familia es la institución social principal, la misma que une a las personas vinculadas por nacimiento o por elección en un hogar y una unidad doméstica. La familia es el entorno donde se establecen por primera vez el comportamiento y las decisiones en materia de salud, la estabilidad emocional y psicológica de los padres es fundamental para el buen funcionamiento de la familia (OMS, 2003).

Se reconoce como familia desde una dimensión social y afectiva a todas las personas unidas entre sí por grados de consanguinidad, lazos afectivos o adopción, las cuales conviven en un mismo espacio físico o en donde sus integrantes viven en diferentes hogares, donde tenemos a la familia extensa o extendida, donde tenemos a los padres e hijos como núcleo básico y todos los parientes (Armas \& Díaz, 2014).

Desde la perspectiva de las ciencias sociales, se entiende que la familia es: "la unidad social básica que está formada alrededor de dos o más adultos conviviendo en la misma casa, son quienes cooperan en actividades económicas, protectoras y sociales sobre el cuidado de los 
hijos, ya sean estos biológicos o adoptados". Es ahí donde se tiene que el concepto de familia, no hace solo referencia a que la pareja de cónyuges tenga entre sí lazos legales ni religiosos, por cuanto, es probable que el mayor nexo entre el hombre y la mujer que deciden vivir juntos es el amor entre los dos (Armas \& Díaz, 2014).

Se debe tener presente que en una familia existe un conjunto de roles, esto resulta interesante, ya que al ver la forma como se distribuyen en la mesa del comedor los integrantes de una familia, se evidencia que la sola distribución de los miembros al momento de comer nos dice quién ejerce el más relevante de los roles con respecto al liderazgo. (Gómez, 2009)

\section{Características de las Familias}

El hogar ha surgido como una unidad socioeconómica fuerte, donde el lugar de la familia está exclusivamente formado por padres e hijos, así como los miembros de la familia ampliada. Se reconoce que la familia tiene una responsabilidad fundamental en la socialización de sus miembros, en su educación, así como en el establecimiento de las normas sociales y los roles de género, donde los efectos de las fuerzas sociales que ejercen presión sobre la familia son dignos de mención.

Las tendencias actuales que se han visto influenciadas por la tecnología, las redes sociales y los divorcios de forma masiva, ha traído consigo que el cuerpo familiar se estructure de una forma monoparental en que la cabeza de serie es la mujer, la misma que pasa a ser población económicamente activa (PEA); y esto hace que el primer matrimonio y el nacimiento de los hijos adquiera promedios más arriba de los 25 años cuando en el pasado ya las mujeres se unían a sus parejas desde los 15 años. Por otro lado, disminuye el número de miembros de la familia, lo cual va cayendo en descenso de los hogares de la década de los 60 - 70 cuyas familias tenían más de ocho miembros, donde al año 2020 llega hasta 4, sin embargo, dentro del aspecto socio económico el hogar se ha hecho más fuerte ya que trabajan padre y madre logrando de esta forma un nivel de vida direccionado a los hijos los cuales pueden aportar a temprana edad con el grupo familiar (OMS, 2003).

Las familias son un reflejo de la comunidad, la cual aporta el primer nivel de educación para sus miembros acerca de los comportamientos saludables que deben adoptarse, sus funciones y responsabilidades con respecto a ellos mismos, la sociedad y los comportamientos perjudiciales que deben evitarse o cambiarse, donde los grupos religiosos y sociales, contribuyen a formar redes de apoyo social; las cuales son necesarias para fortalecer la función de la familia en cuanto a la promoción y la protección de la salud. 
Las familias cuando tienen problemas pueden responder de manera agresiva a todo intento de ayuda, es por ello que existe la desesperanza y la frustración, que contribuyen a desarrollar una incapacidad para afrontar los problemas, todo ello da lugar a que se den manifestaciones tanto de violencia física como emocional, este tipo de familias no comparten actividades positivas de forma colectiva, más bien lo que suelen compartir son las crisis que afectan a la familia, donde las relaciones afectivas están dadas por causa del autoritarismo y el miedo, que muchas veces es ocasionado por la falta de cariño y la tolerancia.

\section{Salud física y psicológica en epoca de pandemia}

Actualmente, el mundo está siendo golpeado por la mayor crisis sanitaria de las últimas décadas, donde se ha obligado a los gobiernos de muchos países a establecer medidas que ayuden a minimizar el contagio entre personas por causa del nuevo virus COVID 19, donde una de las medidas más estrictas para cumplir este propósito es la cuarentena; es decir, el aislamiento, separación y restricción del movimiento normal de las personas en todo el mundo, por cuanto, las personas que potencialmente han estado expuestas a esta enfermedad contagiosa logren evitar el contacto directo con la población y poder así reducir el riesgo potencial de infectar a otros (Abufhelea \& Jeanneret, 2020).

Esto ha generado un aumento del riesgo de maltrato tanto físico como psicológico, al igual que la negligencia al interior de las familias del país y del mundo, donde los miembros de la familia pasan la totalidad del tiempo confinados en los hogares, por tanto, esto ha obligado a que los padres combinen su preocupación y desesperación por el cuidado de los hijos, con la necesidad de cumplir con el teletrabajo dentro de sus hogares, de ahí surge una creciente preocupación por mantener el ingreso económico mínimo requerido. Asimismo, los niños y adolescentes que no pueden asistir a sus aulas de clases y deben adaptarse a los nuevos sistemas tecnológicos para la difusión de clases de manera virtual, provocando el aislamiento social de sus amigos, por cuanto no pueden participar en actividades de interés, y mantienen limitaciones en sus hogares para realizar sus actividades normales, de esta forma se han reprimido las vías habituales de liberación de tensión y energía.

Lo anterior expuesto es el mejor escenario, mas existe otro menos favorable, cuando el proveedor familiar no cuenta con trabajo fijo y la manutención depende de sus ventas diarias; es decir, vendedores informales, cuyos hijos no cuentan con la oportunidad del acceso a la educación virtual, por falta de recursos para contratar un plan de internet, pues existen necesidades básicas más importantes que cubrir, como son la alimentación y la salud. 
Con todo lo antes señalado, se han incrementado los niveles de irritabilidad, ansiedad, impulsividad, e hiperactividad, los mismos que han agregado y agravado las múltiples tensiones a las que se encuentran sometidos los padres o cuidadores, donde esta conjunción de varios factores puede tener un efecto de "olla a presión" y precipitar así accidentes entre familiares, debido al estrés que genera el encierro y la claustrofobia.

Otro aspecto, se da con el aumento de los riesgos de accidentes, muchas intoxicaciones y abusos, causados por la disminución de la supervisión y los cuidados sobre los niños y adolescentes que permanecen aislados en sus hogares, donde sus padres deben salir a trabajar. Esto se da mayormente en niños menores en quienes puede haber un aumento de accidentes domésticos, que muchas veces es causado por una mayor hiperactividad y de igual forma por aburrimiento, esto es por la ausencia de supervisión parental.

En el caso de los adolescentes, surge el aburrimiento al igual que la búsqueda de sucesos, donde les lleva a permanecer mayor tiempo de exposición en sus computadores y conexión a redes sociales, donde no tienen supervisión de contenidos, así como contactos peligrosos, donde muchos suelen ser de mafias de secuestradores o abusadores.

Durante época de pandemia ha persistido una amplia variedad de riesgos asociados al estrés psicosocial y a trastornos de salud tanto mental como física, al igual que los efectos secundarios del confinamiento. Se debe conocer que la sobrecarga del confinamiento en casa puede inducir en mayor grado a pacientes y familias con antecedentes de salud mental, dado que existe evidencia de que los desastres que causa esta patología en las personas, afectan de manera desmedida a las familias que son en su mayoría pobres y vulnerables, estos pacientes son quienes pueden estar entre los más afectados (Alcaina, 2006).

En otro aspecto, esta enfermedad causada por el (SARS-CoV-2) COVID 19, es sin lugar a duda una crisis que puede convertirse también en una oportunidad en muchos hogares, ya que pueden aprovechar esta pandemia para darle un sentido positivo y esperanzador a sus hogares, debido a que son pocas ocasiones en la historia donde han existido momentos en que las familias se ven forzadas en permanecer "puertas adentro", es ahí que surge, una gran oportunidad que les permita reencontrarse ya sea en las cenas compartidas, en el disfrute de jugar juntos, en las labores del hogar, tener conversaciones sin prisa y de promover en los más jóvenes la autonomía, creatividad, responsabilidad y empatía hacia sus otros miembros del hogar (Aguila \& Gallardo, 2020).

En las familias persiste una angustia, que se ha generado por la enfermedad o muerte de sus seres queridos, provocándoles así muchas patologías entre ellas tenemos: el síndrome de estrés agudo y postraumático, la disminución de la concentración, el insomnio, la irritabilidad, el 
aumento de consumo de alcohol y drogas, la aparición de trastornos depresivos o ansiosos en las familias más vulnerables, donde se puede observar un mayor grado de afectación durante la cuarentena y continuará hasta mucho tiempo después de la pandemia.

\section{Conceptualización del COVID 19}

El síndrome respiratorio agudo severo coronavirus 2 (SARS-CoV-2). Desde su descubrimiento, se han identificado siete cepas patógenas humanas. Dentro de la familia Coronaviridae y la subfamilia Orthocoronavirinae, el alfacoronavirus y el betacoronavirus son transmisibles a los humanos. Se cree que las cepas de alfa y betacoronavirus se originaron de la especie de murciélago (Rousettus leschenaultii). La presentación clínica puede variar ampliamente, desde síntomas leves parecidos al resfriado hasta dificultad respiratoria severa y muerte. (Valencia, 2020)

EI SARS-CoV-2 es el coronavirus responsable de la pandemia de COVID-19 que se presentó a principios del mes de marzo del año 2020 en el Ecuador, y es uno de los siete coronavirus transmisibles humanos que se cree se originó a partir del coronavirus del murciélago. Los primeros casos humanos se documentaron en Wuhan, China, en diciembre del año 2019, por lo tanto, son el resultado de la transmisión a través de un huésped intermedio, probablemente el pangolín. EI COVID19 en los análisis efectuados por la Organización Mundial de la Salud (OMS); y el Centro de Control para la Prevención de Enfermedades de EE. UU, así como otras agencias han sido consistentes sobre la necesidad de distanciamiento físico de 1 a $2 \mathrm{~m}$, pero están en conflicto con el tema de la protección respiratoria con una máscara facial o un respirador (Valencia, 2020).

Se debe entender que la infección por SARS-CoV-2 es una enfermedad sistémica, donde existe un desencadenante infeccioso debido a este virus, produce básicamente un cuadro viral que se puede complicar con una neumonía más o menos grave, donde se presenta una respuesta inmunológica con manifestaciones sistémicas. (Callejas Rubio Jl. et al., 2020)

\section{Impacto de la pandemia por COVID 19 en la salud física y psicológica de la población.}

El primer caso que se dio en América Latina de COVID-19, fue registrado en Brasil el 26 de febrero, esta fue la primera muerte por causa de la infección, donde los primeros casos confirmados fueron personas que llegaron al país desde el exterior, así en las siguientes semanas ya se habían multiplicado las infecciones por transmisión local. Para el 6 de abril del año 2020, América Latina acumulaba más de 27.000 casos de contagios confirmados y un 
promedio de 900 fallecidos, para esa fecha Brasil tenía 10.278 casos, siendo el país más afectado, seguido de Chile con 4.161 y Ecuador con un promedio de 3.465 (Pierre, 2020).

La OMS realizó la descripción de cuatro posibles escenarios de transmisión, donde sugirió planes concretos de acción, clasificando a los países en varias categorías: países con transmisión comunitaria demostrada y en fase de diseminación, países sin casos registrados, con primeros casos registrados y con primeros focos identificados; para entonces, la mayoría de los países latinoamericanos pertenecieron al primer grupo, donde se tuvo una alta tasa de casos que son producto de transmisión local al igual que un crecimiento rápido de contagios a nivel regional, lo cual se dio de forma particular en zonas como la región del Guayas en Ecuador y Sao Paulo, en Brasil, siendo los países más afectados. (OMS, 2020)

A medida que gran parte del mundo comienza a aliviar los cierres patronales, a nivel mundial la pandemia aún puede estar en su infancia, con más de 160000 casos nuevos reportados cada día desde el 25 de junio. Cada país cuenta los casos de manera diferente, por lo que las comparaciones directas son difíciles, pero los números ilustran un patrón preocupante. A nivel sub-nacional, la imagen está matizada, con puntos calientes locales, pero a nivel de país, la imagen es clara: el mundo se enfrenta a una pandemia multipolar cada vez más grave (The Lancet, 2020).

La pandemia trajo consigo las tensiones que surgen de los intereses de las comunidades versus los individuos. Los nacidos durante esta enfermedad que se ha extendido por todo el mundo, pasaron a convertirse en "una generación disminuida", así las tasas de tabaquismo aumentaron debido a que el encierro propino una aceleración a los adictos al alquitrán envueltos en un cigarrillo, naciendo así otro eslabón al control de las enfermedades virales, poniendo en relevo la importancia de las disciplinas; virología y epidemiologia que aportan al desempeño de la población para que pueda contrarrestar las enfermedades que generan la aparición de estas pandemias y de alguna forma bajar los niveles de vulnerabilidad, el cual ha quedado establecido que no tiene límites ni de nivel económico ni social ni racial (Horton, 2020).

El impacto de la pandemia por COVID 19, en la salud pública, puso en relieve las medidas adoptadas por gobernantes y políticos, dando impulso a la medicina en sus diferentes divisiones funcionales como son: las emergencias, las áreas de consulta externa y las unidades de cuidados intensivos, por cuanto la salud con estos virus se volvió para su tratamiento interdisciplinario, además toma en cuenta un proceso clínico-psicológico para tratar a los pacientes que también se han visto afectados por el encierro y el stress (López et al., 2020). 
De forma positiva y paradójica, las sociedades han prosperado después de sufrir graves catástrofes, como, por ejemplo, la pandemia de gripe acontecida en la década de 1920, desde ahí surgió un período de crecimiento económico próspero. Debemos tener seguridad de que los efectos de COVID-19 serán profundos y duraderos, por cuanto la pandemia dejará a una población más pequeña pero más saludable. Aunque esto ha causado mucho sufrimiento tanto personal como colectivo, así como una catástrofe económica, de todo esto se debe extraer las mejores lecciones aprendidas que nos permitan mejorar el sistema sanitario actual (García \& Gómez, 2020).

Es necesario considerar las posibles consecuencias de esta pandemia para nuestras sociedades y en especial en las familias de escasos recursos, donde se han presentado gran cantidad de muertes, asimismo se han creado nuevas oleadas de xenofobia contra los chinos donde fue el primer foco de contagios. Los gobiernos serán siempre acusados de no hacer lo suficiente, también se producirá una crisis intelectual, debido a que está afectando a las sociedades de todo el mundo, dejando así en una situación sin precedentes a la población mundial (Horton, 2020).

\section{Cultura y su efecto en épocas de pandemia}

Esta época de pandemia ha provocado que muchas personas y familias permanezcan mucho más tiempo en casa, de lo que acostumbraban a permanecer, sin embargo, esto ha inducido a mantener confinamiento en donde el mundo se ha volcado hacia el arte y la cultura.

Se hace realmente notorio, el valor que representa la música, el arte, el cine, la literatura, el baile, y todas las disciplinas de contenido cultural, en estos momentos de distanciamiento físico, pues la población del mundo acude a estas, con el fin de encontrar calma, reducir la ansiedad, liberar el estrés que ha sido provocado por el confinamiento.

Se entiende así que la cultura, es el conjunto de los rasgos distintivos, espirituales y materiales, intelectuales y afectivos que caracterizan a una sociedad o un grupo social, en ella se engloban, el arte y letras, los derechos fundamentales, los modos de vida, al ser humano, los sistemas de valores y todas las tradiciones y creencias existentes.

\section{Factores que afectan al desempeño físico y psicológico de la sociedad ecuatoriana}

En la sociedad occidental actual, predominan las afectaciones tanto físicas como psicológicas, donde esto muchas veces afecta a su desempeño normal, esto quiere decir, que las personas no toman en consideración los cambios que se han originado por causa de la pandemia donde los principales factores que afectan a su desempeño tanto físico como psicológico se ha dado 
por la degradación en la salud, ya que han surgido eventos catastróficos, por ende, esta fragilidad de nuestros sistemas de salud ha quedado al descubierto como nunca antes (Díaz, 2020).

El profundo impacto del colapso de los sistemas de salud en nuestras estructuras sociales, económicas y políticas es obvio, y tendrá graves consecuencias a mediano y largo plazo. Aunque ningún líder puede ignorar la necesidad apremiante de una mejor gobernanza del sistema de salud pública por más tiempo, será nuestra responsabilidad, como ciudadanos, asegurar que estos temas estén en la parte superior de la agenda política. La pandemia por COVID-19 ha tenido, tiene y tendrá un impacto demoledor en los sistemas de salud y en la vida de las personas, así como un gran efecto en el desempeño físico y psicológico de la sociedad ecuatoriana (Mestres, 2020).

Hay que tener en cuenta que la toma de conciencia entre la población es el primer paso para lograr algún tipo de cambio social, pero si los programas que se supone, van encaminados a dicha labor, se muestran insuficientes, difícilmente se va a conseguir luchar contra la pandemia, pues lo mismo sucede cuando se quieren cambiar los hábitos comportamentales o prevenir los contagios futuros donde es importante, seguir los protocolos de prevención para así tener el control sobre los aspectos psicológicos que van a mediar, de forma que la persona comprenda que aquello se le dice por su bien y su salud futura.

\section{MATERIALES Y MÉTODOS}

El objetivo de la presente investigación es demostrar teóricamente los efectos en la salud física y psicológica en las familias de la sociedad ecuatoriana en tiempo de pandemia. De acuerdo al tipo de investigación: para la obtención de información se utilizó una metodología descriptiva, no experimental y retrospectiva durante el periodo febrero a junio del año 2020, tanto con fuentes primarias como fuentes secundarias (Bernal, 2010).

Basándose en la siguiente temática:

- Obtención de información cualitativa mediante las plataformas webs con literatura científico-académica: Elsevier, The Lancet, EBSCOHost, Google Scholar [Google Académico], SciELO, Redalyc.org y Dialnet.

- Recopilar toda la información posible existente, para lo cual se remitió a otras fuentes de información de artículos científicos que corresponden a editoriales de revistas y libros que han realizado estudios en el mundo.

Con la información obtenida se realizó: Análisis referencial, elaboración de cuadros esquemáticos, recomendaciones para futuros estudios y conclusiones. 


\section{ANÁLISIS DE LOS RESULTADOS}

Se inició el análisis a partir de la información de cifras estadísticas de la población contagiada por COVID 19 y fallecidos a nivel nacional por cada provincia del Ecuador en el periodo comprendido entre los meses de febrero a junio del año 2020, para poder determinar el impacto causado por casos contagiados por COVID 19, se ha recurrido a un análisis estadístico, con la aplicación: a) Estadística descriptiva básica; b) Análisis de pruebas no paramétricas: Chi cuadrado para prototipos cualitativos, donde se ha tomado como muestra a la población contagiada y fallecidos durante la pandemia hasta el corte del 7 de julio del año 2020 por cada provincia del Ecuador.

\section{Tabla 1}

Casos confirmados por COVID 19 (febrero - julio, 2020).

\begin{tabular}{l|r|r|r}
\hline \multicolumn{1}{|c|}{ Provincia } & Confirmado & \%Conirmado & Fallecidos \\
\hline Azuay & 2.011 & $3,70 \%$ & 69 \\
Bolivar & 781 & $1,44 \%$ & 41 \\
Cañar & 566 & $1,04 \%$ & 45 \\
Carchi & 382 & $0,70 \%$ & 19 \\
Chimborazo & 868 & $1,60 \%$ & 162 \\
Cotopaxi & 1.285 & $2,37 \%$ & 131 \\
El Oro & 2.192 & $4,04 \%$ & 282 \\
Esmeraldas & 2.240 & $4,13 \%$ & 150 \\
Galápagos & 100 & $0,18 \%$ & 1 \\
Guayas & 16.176 & $29,80 \%$ & 1.625 \\
Imbabura & 739 & $1,36 \%$ & 45 \\
\hline Loja & 1.152 & $2,12 \%$ & 52 \\
Los Ríos & 2.472 & $4,55 \%$ & 277 \\
\hline Manabí & 4.798 & $8,84 \%$ & 648 \\
Morona Santiago & 1.090 & $2,01 \%$ & 12 \\
Napo & 660 & $1,22 \%$ & 37 \\
Orellana & 841 & $1,55 \%$ & 24 \\
Pastaza & 899 & $1,66 \%$ & 31 \\
Pichincha & 9.191 & $16,93 \%$ & 563 \\
Santa Elena & 969 & $1,78 \%$ & 326 \\
Sto. Domingo Tsáchilas & 2.407 & $4,43 \%$ & 160 \\
\hline Sucumbíos & 527 & $0,97 \%$ & 22 \\
Tungurahua & 1.301 & $2,40 \%$ & 127 \\
Zamora Chinchipe & 642 & $1,18 \%$ & 24 \\
\hline Total general & 54.289 & $100 \%$ & 4.873 \\
\hline
\end{tabular}

Fuente: Ministerio de Salud Pública (2020). 
Tabla 2

Población contagiados/fallecidos por provincia.

\begin{tabular}{|c|c|c|c|c|}
\hline \multirow{2}{*}{ PROYINCIA } & \multicolumn{2}{|c|}{ COYID 19} & \multirow{2}{*}{$\begin{array}{l}\text { NUMERO DE } \\
\text { HABITANTES }\end{array}$} & \multirow{2}{*}{$\begin{array}{l}\text { SUPERFICIE } \\
\qquad \mathrm{km} 2\end{array}$} \\
\hline & Contagiados & Fallecidos & & \\
\hline Azuay & 2.011 & 69 & 881.394 & $8.309,58$ \\
\hline Bolívar & 781 & 41 & 209.933 & $3.945,38$ \\
\hline Cañar & 566 & 45 & 281.396 & $3.146,08$ \\
\hline Carchi & 382 & 19 & 186.869 & $3.780,45$ \\
\hline Chimborazo & 868 & 162 & 524.004 & $6.499,72$ \\
\hline Cotopaxi & 1.285 & 131 & 488.716 & $6.108,23$ \\
\hline ElOro & 2.192 & 282 & 715.751 & $5.766,68$ \\
\hline Esmeraldas & 2.240 & 150 & 643.654 & $16.132,23$ \\
\hline Galápagos & 100 & 1 & 33.042 & $8.010,00$ \\
\hline Guayas & 16.176 & 1.625 & 4.387 .434 & $15.430,40$ \\
\hline Imbabura & 739 & 45 & 476.257 & $4.587,51$ \\
\hline Loja & 1.152 & 52 & 521.154 & $11.062,73$ \\
\hline Los Ríos & 2.472 & 277 & 921.763 & $7.205,27$ \\
\hline Manabí & 4.798 & 648 & 1.562 .079 & $18.939,60$ \\
\hline Morona Santiago & 1.090 & 12 & 196.535 & $24.059,40$ \\
\hline Napo & 660 & 37 & 133.705 & $12.542,50$ \\
\hline Orellana & 841 & 24 & 161.338 & $21.692,10$ \\
\hline Pastaza & 899 & 31 & 114.202 & $29.641,37$ \\
\hline Pichincha & 9.191 & 563 & 3.228 .233 & $9.535,91$ \\
\hline Santa Elena & 969 & 326 & 401.178 & $3.690,17$ \\
\hline $\begin{array}{l}\text { Sto. Domingo } \\
\text { Tsáchilas }\end{array}$ & 2.407 & 160 & 458.580 & $3.446,65$ \\
\hline Sucumbíos & 527 & 22 & 230.503 & $18.084,42$ \\
\hline Tungurahua & 1.301 & 127 & 590.600 & $3.386,25$ \\
\hline Zamora Chinchipe & 642 & 24 & 120.416 & $10.584,28$ \\
\hline TOTAL & 54.289 & 4.873 & 17.468 .736 & $255.586,91$ \\
\hline
\end{tabular}

Fuente: Elaboración propia a partir de la Tabla 1. 
Tabla 3

Densidad poblacional contagiados/fallecidos COVID-19.

\begin{tabular}{|c|c|c|}
\hline \multirow{2}{*}{ PFAYILICIA } & \multicolumn{2}{|c|}{ DENSIDAD POELACIDHAL } \\
\hline & Contagiados & Falletidos \\
\hline Azuay & 0,24 & 0,01 \\
\hline Bolívar & 0,20 & 0,01 \\
\hline Cañar & 0,18 & 0,01 \\
\hline Carchi & 0,10 & 0,01 \\
\hline Chimborazo & 0,13 & 0,02 \\
\hline Cotopaxi & 0,21 & 0,02 \\
\hline El Oro & 0,38 & 0,05 \\
\hline Esmeraldas & 0,14 & 0,01 \\
\hline Galápagos & 0,01 & 0,00 \\
\hline Guayas & 1,05 & 0,11 \\
\hline Imbabura & 0,16 & 0,01 \\
\hline Loja & 0,10 & 0,00 \\
\hline Los Ríos & 0,34 & 0,04 \\
\hline Manabí & 0,25 & 0,03 \\
\hline Morona Santiago & 0,05 & 0,00 \\
\hline Napo & 0,05 & 0,00 \\
\hline Orellana & 0,04 & 0,00 \\
\hline Pastaza & 0,03 & 0,00 \\
\hline Pichincha & 0,96 & 0,06 \\
\hline Santa Elena & 0,26 & 0,09 \\
\hline $\begin{array}{c}\text { Sto. Domingo } \\
\text { Tsáchilas }\end{array}$ & 0,70 & 0,05 \\
\hline Sucumbíos & 0,03 & 0,00 \\
\hline Tungurahua & 0,38 & 0,04 \\
\hline Zamora Chinchipe & 0,06 & 0,00 \\
\hline TOTAL & 0,51 & 0,04 \\
\hline
\end{tabular}

Fuente: Elaboración propia a partir de la Tabla 2 
Tabla 4

Casos contagiados por provincia.

\begin{tabular}{|c|c|c|}
\hline Provincia & Confirmados & $\%$ de Part. \\
\hline Azuay & 2.011 & 3,7 \\
\hline Bolivar & 781 & 1,44 \\
\hline Cañar & 566 & 1,04 \\
\hline Carchi & 382 & 0,7 \\
\hline Chimborazo & 868 & 1,6 \\
\hline Cotopaxi & 1.285 & 2,37 \\
\hline El Oro & 2.192 & 4,04 \\
\hline Esmeraldas & 2.240 & 4,13 \\
\hline Galápagos & 100 & 0,18 \\
\hline Guayas & 16.176 & 29,8 \\
\hline Imbabura & 739 & 1,36 \\
\hline Loja & 1.152 & 2,12 \\
\hline Los Ríos & 2.472 & 4,55 \\
\hline Manabí & 4.798 & 8,84 \\
\hline Morona Santiago & 1.090 & 2,01 \\
\hline Napo & 660 & 1,22 \\
\hline Orellana & 841 & 1,55 \\
\hline Pastaza & 899 & 1,66 \\
\hline Pichincha & 9.191 & 16,93 \\
\hline Santa Elena & 969 & 1,78 \\
\hline $\begin{array}{l}\text { Sto. Domingo } \\
\text { Tsáchilas }\end{array}$ & 2.407 & 4,43 \\
\hline Sucumbíos & 527 & 0,97 \\
\hline Tungurahua & 1.301 & 2,4 \\
\hline $\begin{array}{c}\text { Zamora } \\
\text { Chinchipe }\end{array}$ & 642 & 1,18 \\
\hline Total & 54289 & 100 \\
\hline
\end{tabular}

Fuente: Elaboración propia a partir de la Tabla 2. 


\section{Variación del número total de casos contagiados} por provincias

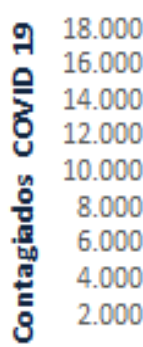

- Confirmados $\%$ dePart.

Figura 1. Variación del número total casos contagiados por provincias.

Fuente: Elaboración propia a partir de la Tabla 4.

En la tablas y figura se puede observar los casos confirmados por COVID 19 en el periodo antes señalado por provincia; donde la tendencia más alta es en Guayas y Pichincha, hasta julio del año 2020.

\section{Correlación de contagiados por COVID 19 con número de habitantes}

Tabla 5

\section{Estadisticas de la regresión}

Coeficiente de correlación

múltiple

0,98254313

Coeficiente de

determinación $\mathrm{R}^{n} 2$

0,965391

$\mathrm{R}^{\wedge} 2$ ajustado

0,96381787

Error típico

668,350289

Observaciones 
ANÁLISIS DE VARIANZA

\begin{tabular}{|c|c|c|c|c|c|}
\hline & $\begin{array}{l}\text { Grados de } \\
\text { libertad }\end{array}$ & $\begin{array}{l}\text { Suma de } \\
\text { cuadrados }\end{array}$ & $\begin{array}{c}\text { Promedio de los } \\
\text { cuadrados }\end{array}$ & $F$ & $\begin{array}{c}\text { Valor crítico } \\
\text { de F }\end{array}$ \\
\hline Regresión & & 274122825 & 274122824,6 & 613,672861 & $1,4584 \mathrm{E}-17$ \\
\hline Residuos & 2 & 9827226,39 & 446692,1088 & & \\
\hline Total & 2 & 283950051 & & & \\
\hline
\end{tabular}

\begin{tabular}{lrrr} 
& Coeficientes & Error tipico & \multicolumn{1}{c}{ Estadisticot } \\
\hline Intercepción & $-197,664739$ & 168,733807 & $-1,171459013$ \\
NUMMERO DE HABITANTE & 0,00337935 & 0,00013642 & 24,77242139 \\
\hline
\end{tabular}

\begin{tabular}{ccccc}
\hline & Superior & Inferior & Superior \\
Probabilidad Inferior $95 \%$ & $95 \%$ & $95,0 \%$ & $95,0 \%$ \\
\hline 0,25394589 & $-547,597237$ & 152,267759 & $-547,597237$ & 152,267759 \\
$1,4584 \mathrm{E}-17$ & 0,00309644 & 0,00366226 & 0,00309644 & 0,00366226 \\
\hline
\end{tabular}

Fuente: Elaboración propia a partir de la Tabla 2.

La distribución espacial de los casos de contagiados por COVID 19 fue proporcional al total de habitantes por casos registrados en cada provincia. La correlación entre el número de contagiados y el número de habitantes para el período analizado por provincia resultó positiva y significativa $(R=0,98, P<0,01, n=24)$, lo que indica que los territorios con mayor número de habitantes registraron los mayores números de casos de contagio del virus. 
Análisis de pruebas no paramétricas: Chi cuadrado para muestras cualitativas

Tabla 6

Contagiados / fallecidos por COVID - 19.

\begin{tabular}{r|rrr}
\multicolumn{1}{l}{ fo } & \multicolumn{1}{c}{ fe } & fo $-f e$ & $(f o-f e)^{2}$ \\
\hline 2011 & 1909 & 69 & 171,32 \\
781 & 754 & 41 & 67,71 \\
566 & 561 & 45 & 50,33 \\
382 & 368 & 19 & 33,03 \\
868 & 945 & 162 & 84,84 \\
1285 & 1299 & 131 & 116,63 \\
2192 & 2270 & 282 & 203,78 \\
2240 & 2193 & 150 & 196,86 \\
100 & 93 & 1 & 8,32 \\
16176 & 16335 & 1625 & 1466,22 \\
739 & 719 & 45 & 64,58 \\
1152 & 1105 & 52 & 99,17 \\
2472 & 2523 & 277 & 226,43 \\
4798 & 4997 & 648 & 448,57 \\
1090 & 1011 & 12 & 90,77 \\
660 & 640 & 37 & 57,41 \\
841 & 794 & 24 & 71,25 \\
899 & 853 & 31 & 76,60 \\
\hline 9191 & 8951 & 563 & 803,41 \\
\hline 969 & 1188 & 326 & 106,67 \\
\hline 2407 & 2356 & 160 & 211,44 \\
527 & 504 & 22 & 45,22 \\
\hline 1301 & 1310 & 127 & 117,62 \\
\hline 54289 & 611 & 24 & 54,86 \\
\hline & 54289 & 4873 & 4873
\end{tabular}

Fuente: Elaboración propia a partir de la Tabla 2.

$$
x^{2}=\Sigma\left[\frac{\left(f_{0}-f_{e}\right)^{2}}{f_{e}}\right]
$$

$$
x^{2}=1.136
$$

\section{Prueba de Hipótesis}

Ho: No existe una relación entre los contagiados por COVID 19 y cantidad de ciudadanos fallecidos durante este periodo. 
H1: Existe una relación entre los contagiados por COVID 19 y cantidad de ciudadanos fallecidos durante este periodo

Prueba de significancia de Chi cuadrado

gl = (número de renglones -1$)$ número de columnas - 1)

$r=24$

$c=4$

gl $=(24-1) *(4-1)$

gl $=23$

\section{Nivel de significancia $=0,01$}

De acuerdo a la tabla $=41,6$

Debido a que el valor calculado es mayor que el valor de la tabla, se rechaza hipótesis nula, por ende, existe una relación directa entre los contagiados por COVID-19 y cantidad de ciudadanos fallecidos durante este periodo, y se acepta la alternativa, a un nivel de significancia de 0,01 .

\section{DISCUSIÓN}

Este estudio es una revisión teórica, recopilada de documentos que analizan la Teoría sobre el impacto en la salud física y psicológica en las familias de la sociedad ecuatoriana en tiempo de pandemia, su impacto en los hogares de menores ingresos, en los que la demanda de cuidados es mayor. De esta forma se acentúan muchas desigualdades, ya que es muy difícil mantener el distanciamiento social cuando las personas contagiadas habitan en viviendas que no cuentan con el espacio físico necesario que les permita mantener el distanciamiento frente a los grupos de alto riesgo de exposición al virus.

El impacto que ha causado la pandemia en las familias de la sociedad ecuatoriana, en primer lugar, se debe a que los jóvenes adultos deben salir a realizar diversas actividades elevando así el índice de contagios, asimismo los estudiantes de menores recursos no pueden continuar con su educación a través de medios digitales, ya que no todos los hogares ni centros educativos disponen de las herramientas, las capacidades y las tecnologías necesarias para operar en esta modalidad, todo esto ha provocado problemas psicológicos en las familias de estratos sociales bajos (Torrente, 2020).

Según los datos de la CEPAL a 2017, se obtiene que un 52,2\% de los hogares del Caribe y Latinoamérica tenían acceso a Internet, mientras que un 44,7\% disponían de recursos tecnológicos; si se desea implementar la modalidad de educación a distancia, se requiere que los maestros cuenten con una serie de habilidades y capacidades en lo referente a clases 
virtuales para los profesores del sector educativo, esto con el objetivo de volver más eficiente a las empleadas mujeres que representan un 69,8\%, y quienes al trabajar en casa cumplen doble función el de maestras y madres que relacionan a las actividades del hogar, de esta forma es evidente el uso de la tecnología, debido a que facilita el acceso a la educación online (CEPAL, 2020).

Durante el tiempo de pandemia, ha sido necesario la utilización de tecnologías, la información y las comunicaciones necesarias para implementar la educación por medio de recursos tecnológicos, por cuanto se tienen habilidades que poseen tanto los estudiantes, así como los profesionales de la educación; para las familias de la sociedad ecuatoriana, esto ha resultado ser un gran desafío.

\section{CONCLUSIONES}

Existe alta complejidad del problema en época de pandemia, donde se han manejado unas cantidades de contagios y decesos que, sin caer en cuenta estos números apenas permiten calcular el riesgo en los sistemas complejos; donde los sistemas sanitarios actualmente tienen una capacidad limitada, debido a que los mismos no pueden tratar a la vez más que a una cierta cantidad de personas, en donde sus unidades especializadas (UCI), han actuado de manera ineficiente, esto es porque ha existido una avalancha de enfermos graves, en donde es evidente que la crisis no ha sido abordada con esta perspectiva en todas sus fases.

Para ello es necesario actuar de manera coordinada a nivel nacional, realizando acciones colectivas, las cuales permitan hacer frente a la crisis sanitaria que está afectando en gran magnitud a la sociedad ecuatoriana, por cuanto ha surgido un gran impacto en su salud física y psicológica de las familias en la sociedad ecuatoriana, así como los efectos diferenciados que esta crisis tendrá sobre sus vidas en el país. Por ello las políticas y medidas que se evalúen deben tener presente cuáles serán las consecuencias psicológicas como: estrés, ansiedad, miedo y soledad y físicas: enfermedades desarrolladas durante la crisis sanitaria en las familias de la sociedad ecuatoriana.

Las estrategias que se adopten para enfrentar el efecto de la pandemia en la sociedad ecuatoriana deben implementarse fortaleciendo el trabajo coordinado con los mecanismos necesarios para el adelanto de las familias en el país, y contando con la participación de las organizaciones y los movimientos de protección a las familias, con el fin de que contribuyan al diseño de estas estrategias adaptándolas a sus realidades.

En este contexto de crisis, cuando el actual sistema de organización económica deja en evidencia que, en los cuidados de la salud, así como la generación de las condiciones que 
garantizan la vida de las personas, esto resulta imprescindible, de esta manera, se deba visibilizar y redistribuir este trabajo en los hogares donde las mujeres son las que realizan mayormente el trabajo, tanto dentro como fuera de los hogares. Es necesario advertir que uno de los desafíos más importantes que tiene la región es realizar una correcta organización social de los cuidados, que le permitan alcanzar la plena corresponsabilidad entre el Estado, la sociedad y las familias.

\section{REFERENCIAS BIBLIOGRÁFICAS}

Abufhelea, M., \& Jeanneret, V. (2020). Puertas Adentro: La otra cara de la Pandemia. 91(3), 319-321.

Aguila, S., \& Gallardo, M. (2020). C. COVID-19 y la esperanza de la inmunidad. Aten Primaria. https://doi.org/10.1016/j.aprim.2020.05.004, 1-2.

Alcaina, T. (2006). Sicopatología e Interacción Familiar.

Armas, N., \& Díaz, L. (2014). Entre voces y silencios, la familia por dentro. Recuperado de https://aprenderly.com/doc/1346496/familias-por-dentro---sociedad-ecuatoriana-demedicina-fa...

Bernal, C. A. (2010). Metodología de la investigación. Tercera edición (Vols. ISBN: 978-958699-128-5). Bogotá: PEARSON EDUCACIÓN, Colombia.

Callejas Rubio Jl. et al. (2020). Oneworld, one health: The novel coronavirus COVID-19 epidemic. MedClin(Barc). https://doi.org/10.1016/j.medcli.2020.05.015, 1.

CEPAL. (2020). La pandemia del COVID-19 profundiza la crisis de los cuidados en América Latina y el Caribe. Obtenido de Datos obtenidos de Comisión Económica para América Latina y el Caribe (CEPAL), CEPALSTAT [en línea] https://estadisticas.cepal.org/cepalstat/Portada.html) el 20 de marzo de 2020

Díaz, T. J. (2020). COVID - 19: What's next? Gastroenterol Hepatol. https://doi.org/10.1016/j.gastrohep.2020.05.001, 2.

Dilleggi, E. S., Rosa, A. P., \& Santos, P. L. (2019). Family functioning and environmental resources offered by families. SALUD MENTAL, 42 (5), 235-242.

García, A. J., \& Gómez, H. R. (2020). COVID-19 disease the hospital of the future is already here. Rev Clin Esp. https://doi.org/10.1016/j.rce.2020.05.010,1-3.

Gómez, R. L. (2009). Dysfunctional Families: One Central Theme in Two Fictional Works of Tony Morrison, Song of Solomon and Sula. FOLIOS, 29, 1-10.

Horton, R. (13 de junio de 2020). Offline: COVID -19 - what we can expect to come. THE LANCET, 395, 1. 
López et al. (2020). Impacto de la pandemia COVID-19 en la atención al paciente con cefalea en Espana: análisis de situación con una mirada al futuro. Neurología, 1-9.

Mestres, C. A. (2020). COVID-19: una pandemia de valores y algo más. GastroenterolHepatol, https://doi.org/10.1016/j.gastrohep.2020.05.006.

OMS. (2003). La familia y la Salud. Washington, D.C.: 44 Consejo Directivo $55^{\circ}$ Sesión del Comité Regional.

OMS. (2020). Enfermedad por coronavirus (COVID-19). Recuperado de https://www.who.int/es/emergencies/diseases/novel-coronavirus-2019/advice-forpublic/q-acoronaviruses?gclid=Cj0KCQjw0rr4BRCtARIsAB0_48O9ihyOSTv6MBzAiCB5jEechm87 aCMAmiM_C_RcesIm5lkdQd36fmlaAshpEALw_wcB

Pierre, A. R. (2020). COVID-19 in Latin America: Challenges and opportunities. Rev Chil Pediatr., 91(2), 179-182, 4.

The Lancet. (11 de julio de 2020). COVID-19: the worst may be yet to come. THE LANCET, 396, 1.

Torrente, B. G. (2020). COVID-19 disease: the hospital of the future is already here. Rev Clin Esp. http://www.elsevier.es/rce, 1-3.

Valencia, D. N. (2020). Brief Review on COVID-19: The 2020 Pandemic Caused by SARS-CoV2. Cureus 12(3), 1-13 e7386. DOI: 10.7759/cureus 